\title{
Radial Artery Patency after Trans-radial Cardiac Catheterization in a Bangladeshi Population
}

\author{
MASHHUD ZIA CHOWDHURY ${ }^{1}$, C M SHAHEEN KABIR ${ }^{1}$, SAHELANASRIN ${ }^{1}$, HEMANTAI GOMES ${ }^{1}$, \\ MD. ENAMUL HAKIM ${ }^{2}$, SAIDUR RAHMAN KHAN ${ }^{1}$, M MAKSUMUL HAQ ${ }^{1}$
}

${ }^{1}$ Department of Cardiology, Ibrahim Cardiac Hospital \& Research Institute, Dhaka, Bangladesh, ${ }^{2}$ Department of Vascular Surgery, National Institute of Cardiovascular Diseases (NICVD), Dhaka, Bangladesh

Address of Correspondence: Dr Mashhud Zia Chowdhury, Associate Professor \& Consultant, Department of Cardiology, Ibrahim Cardiac Hospital \& Research Institute, Dhaka, Bangladesh, e mail: mashhudzia@yahoo.com

\begin{abstract}
:
Background: Transradial cardiac catheterization (TCC) is now preferred method over trans-femoral approach globally including Bangladesh. But the incidence of radial artery occlusion (RAO) after TCC is not infrequent and it ranges from 1-18\% in different studies. The aim of our study was to see the incidence of RAO after TCC in a population coming for coronary angiogram and/or coronary intervention and also to evaluate the factors responsible for RAO. Methods: The observational prospective study was performed in all consecutive patients coming for TCC. Pre and three month post-procedural modified Allen's test, reverse Barbeau test \& Duplex ultrasonography for radial artery diameter (RAD), peak systolic velocity (PSV), end-diastolic velocity (EDV) and resistance index (RI) were measured. Results: 69 patients underwent TCC. Mean age was 54 years, 67\% were male, $80 \%$ hypertensive, 65\% diabetic. Follow-up at third month showed one total RAO (1.45\%) and mean $R A D$ of the remaining patients was significantly reduced from $2.2 \pm 0.03 \mathrm{~mm}$ to $2.1 \pm 0.03 \mathrm{~mm}(p=0.001)$ but none had any symptom or sign of ischemic hand. PSV, EDV \& RI were not significantly altered. Reduction of $R A D$ (to $<2.0 \mathrm{~mm}$ ) were significantly higher in female ( $p=0.032)$, but no association was found in presence of diabetes or its duration, hypertension, dyslipidaemia, smoking, peripheral vascular disease. The size \& number of catheters used or duration of vascular access sheath kept in the artery did not affect the reduction of RAD.Conclusion: The mean RAD of the study was smaller than other study population, but incidence of RAO is very low. RAD was significantly reduced after procedure without any clinical evidence of ischemia or alteration of flow velocity. Female sex was the only factor found to be associated with reduction of RAD in this study.
\end{abstract}

Key words: Transradial cardiac catheterization (TCC), radial artery diameter (RAD).

Introduction:

The trans-radial approach for cardiac catheterization is gaining popularity globally over the trans-femoral approach because of its lower risk of vascular access complications including major bleeding, lower cost and more comfortability especially for conservative females. But post-procedural permanent radial artery occlusion is not so infrequent and it ranges from $1-18 \%$ in different studies $^{1-7}$. Radial artery occlusion (RAO) is usually clinically silent because of dual blood supply of the palm by radial and ulnar artery ${ }^{8}$ and in only $0.2 \%$ of the patients symptomatic RAO occur, requiring medical attention ${ }^{9}$. This RAO usually occur early after trans-radial catheterization and in $50 \%$ of the cases spontaneous recanalization of the artery occurs within 1-3 months ${ }^{2,4}$. In some patients we may get palpable pulse in spite of complete occlusion caused by retrograde filling of the radial artery through collaterals. In a study only $2 \%$ of the patients had an absence of radial pulse early after trans-radial catheterization but $9 \%$ had undetectable radial flow by color Doppler ${ }^{10}$. So diagnosis of RAO should not only depend on the presence or absence of a radial pulse and should be confirmed by reverse Barbeau test and duplex ultrasonogram. The frequency of RAO depends on many factors such as gender, smoking, patient's co-morbidity (in presence of diabetes mellitus or peripheral vascular disease) \& body weight, the diameter of the radial artery, size of sheath with ratio of the radial artery internal diameter to the external diameter of the arterial sheath, number of catheters used, repeat procedure, procedural duration ${ }^{12-}$ 14 , homeostasis procedure ${ }^{3,14}$ and anticoagulant dose $\mathrm{e}^{1,4,9-}$ 16. Among these, size of the radial artery is one of the important factors and unfortunately in one study mean diameter of radial artery in a Bangladeshi population 
coming for cardiac catheterization was found 2.2+0.3 mm which is a bit smaller then other populations ${ }^{17}$. So accordingly the chances of RAO may be higher in our population. Aim of our study was to see the incidence of RAO after trans-radial cardiac catheterization (TCC) and also evaluate the factors responsible for it.

Methods: The observational prospective study was performed in Ibrahim Cardiac Hospital \& Research Institute, Dhaka, Bangladesh from 1st Jan to 31st Dec, 2014 in all consecutive patients who came for trans-radial coronary angiogram with or without angioplasty after taking approval from the ethical review committee. After proper counseling and informed consent, patients were recruited. Before the procedure, along with physical examinations and routine investigations, following tests were done.

1. Modified Allen's test was done to evaluate the ability of ulnar artery to supply blood to the whole palm, in order to avoid palmer ischemia if the radial artery becomes occluded by the procedure. In this test patients were instructed to clench the fist of the right hand. The radial and ulnar arteries were simultaneously compressed, and the patients were asked to relax the hand. Ulnar artery was then released and the time needed for maximal palmer blush to return was recorded. Return of palmer blush within 5-10 seconds was considered normal (positive modified Allen's test) indicating collateral circulation.

2. Reverse Barbeau test using plethysmography and pulse oximetry was performed to assess patency of radial artery. A pulse oximeter was placed on index finger. The morphology of the plethysmography tracing was noted. The ulnar artery was then occluded by manual pressure and any change in the tracing was noted. Constant reading of pulse oximeter was considered as positive oximetry other wise as negative oxymetry. The response to this maneuver was categorized into 1 of 4 types (Figure $1)$. Type A and type B was considered as uninterrupted arterial filling during ulnar artery occlusion. Type $\mathrm{C}$ represented the recruitment of collaterals. Patients with a type D response indicated absence of collateral flow ${ }^{8}$.

3. Duplex ultrasonography: Ultrasound imaging was done for detailed assessment of patient's radial artery

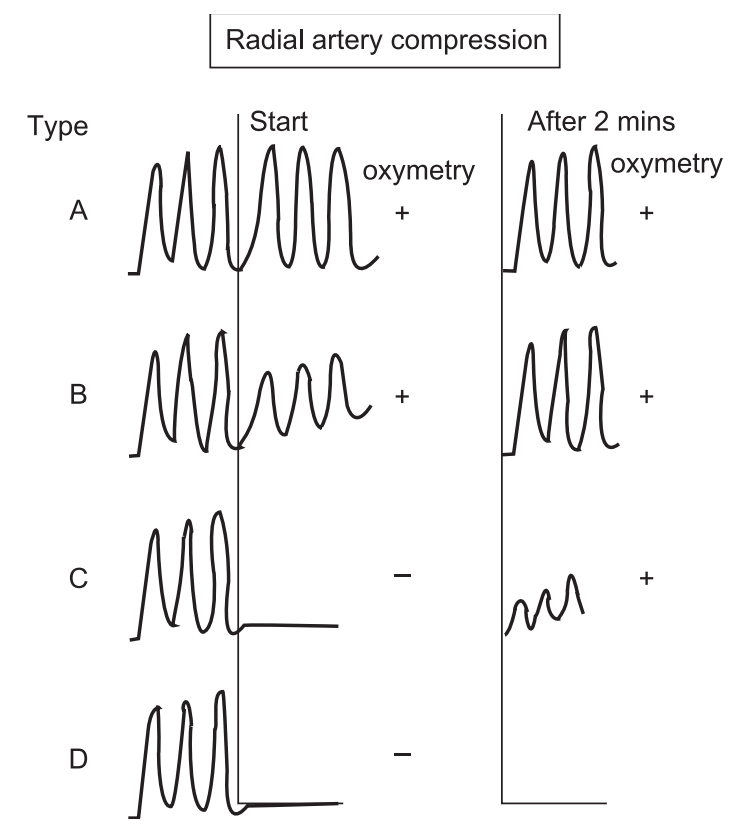

Fig.-1: Reverse Barbeau test

including its size (was measured within $5 \mathrm{~cm}$ of wrist and average of three measurements was taken). Doppler was used to characterize the blood flow in radial artery for assessment of RAO after the procedure. In the radial artery, following parameters was considered; (a) peak systolic velocity (PSV), expressed in cm/sec. (b) end-diastolic velocity (EDV), expressed in cm/sec. (c) resistance index (RI), derived as (PSV-EDV)/ PSV.

All trans-radial procedure was done using same sized puncture needle, sheath (6Fr.) and wire. The dose of heparin was same (2500 unit for diagnostic angiogram and 100 unit /Kg for PCI). In case of PCI, size of guide catheter (5 Fr or 6 Fr) was depended on operator's choice.

Patients with negative modified Allen's test and type C and type $\mathrm{D}$ response on reverse Barbeau test were excluded from the study. After the trans-radial procedure patients were followed up after 1 to 3 days (at time of discharge) on which (a) patient's complain \& sign of ischaemic hand pain were evaluated and if necessary (b) reverse Barbeau test \& (c) Duplex ultrasonography was done to assess radial artery patency.

After 3 months patients were again evaluated to see the RAD and assess the radial artery patency by (a) Patient's complain \& presence of sign of ischaemic hand pain (b) Reverse Barbeau test and (c) Duplex ultrasonography. All procedures were done free of cost and by the same cardiologist under supervision of a vascular surgeon. 
Statistical analysis was done using SPSS 16.0 version. P value $<0.05$ was considered significant.

\section{Results:}

Demographic and clinical characteristics of the subjects: In our study the mean age of the total 69 patients was 53.5 \pm 9.7 years (range: $31-75$ years). Nearly two-thirds (63.8\%) of the patients were 50 or $>50$ years old and $27.5 \%$ 40-50 years. Two thirds (66.7\%) were male. $43.5 \%$ of the patients were overweight and $8.7 \%$ obese (Table I). Approximately $80 \%$ of the patients were hypertensive, $65 \%$ were diabetic, 57\% dyslipidaemic and 38\% had smoking habit. (Fig. 2)

\section{Table-I}

Distribution of study population by their baseline characteristics $(n=69)$

\begin{tabular}{lcc}
\hline Baseline characteristics & Frequency & Percentage \\
\hline Age (years) & & \\
$30-40$ & 6 & 8.7 \\
$40-50$ & 19 & 27.5 \\
$\geq 50$ & 44 & 63.8 \\
Sex & & \\
Male & 46 & 66.7 \\
Female & 23 & 33.3 \\
BMI & & \\
Normal BMI & 33 & 47.8 \\
Obese & 6 & 8.7 \\
Over weight & 30 & 43.5 \\
\hline
\end{tabular}

$*$ Mean age $=(53.5 \pm 9.7)$ years; range $=(31-75)$ years $^{\#}$

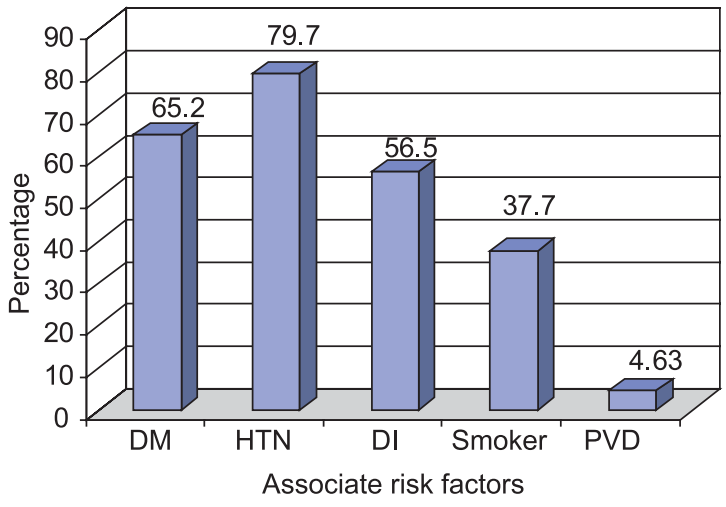

Fig.-2: Distribution of study population by their risk factor $(n=69)$
On pre-procedural checkup 70\% of the patients had Type A response at reverse Barbeau test and rest 30\% had Type $\mathrm{B}$ response. The mean size of the radial artery was $2.2 \pm 0.3$ $\mathrm{mm}$. The mean PSV, EDV and RI were 67.0 $\pm 34.7,5.2 \pm 0.7$ and $0.9 \pm 0.1$ respectively (Table III).

Out of 69 patients, 47 (68.1\%) under went only CAG and rest 22 (31.9\%) either direct PCI or CAG followed by PCI. For all patients 6 Fr vascular access sheath were used and CAG was done using 5 Fr catheters. For PCI either 5 Fr. (31.8\%) or 6 Fr. (68.2\%) guiding catheters were used. Depending on procedure one, two or three catheters (67\%, $23 \%$ and $10 \%$ ) respectively were used. The mean duration of sheath kept in the radial artery i.e. time from sheath insertion to removal was 18.3 minutes for only CAG and 138.4 minutes for CAG with or only PCI. (Table II).

None of the patients had any ischemic symptoms after the procedure at discharge. At around third month of the procedure all of the patients were evaluated. Out of 69 patients one 68 years old lady had radial artery occlusion (1.45\%) detected by absence of radial pulse on examination but without any symptom or sign of ischemic hand. On examination there was positive modified Allen's test but on Doppler study there was no radial artery flow. Remaining 68 patients on post-procedural checkup 50\% of the patients had Type A response at reverse Barbeau test, $47.1 \%$ has Type $\mathrm{B}$ and $2.9 \%$ had Type $\mathrm{C}$ response. The mean size of the radial artery was $2.1 \pm 0.3 \mathrm{~mm}$ which is significantly reduced $(\mathrm{p}=0.001)$. The mean PSV, EDV and RI were $63.7 \pm 28.7,5.7 \pm 0.9$ and $0.9 \pm 0.1$ respectively which were not significantly changed than pre-procedure level (Table III).

The mean radial artery diameter (RAD) was significantly reduced after the procedure without any evidence of hand ischemia or alteration of flow velocity. On the basis of reduction of radial artery diameter, study subjects were categorized into two groups: 23 patients with radial artery diameter reduced to less then $2.0 \mathrm{~mm}$ were categorized under group I and 46 patients with radial artery diameter more then $2.0 \mathrm{~mm}$ were categorized under group II. Diameter of radial artery was reduced significantly more in female $(\mathrm{p}=0.032)$. But between the 2 groups no significant association or correlation was found with presence of diabetes (or with its duration), hypertension, dyslipidaemia, smoking or peripheral vascular disease. Size and number of catheter used and duration of vascular access sheath kept in the artery did not affect the reduction of diameter significantly (Table IV). 
Table-II

Distribution of study population by their procedural factors

\begin{tabular}{|c|c|c|c|}
\hline Variable & Frequency & Percentage & $\mathrm{p}$-value \\
\hline \multicolumn{4}{|l|}{ Type of procedure $(n=69)$} \\
\hline CAG only & 47 & 68.1 & - \\
\hline CAG+PCI \& Elective PCI & 22 & 31.9 & - \\
\hline Size of sheath (6Fr) & 69 & 100.0 & - \\
\hline \multicolumn{4}{|l|}{ Catheter size (for CAG) $(\mathrm{n}=63)$} \\
\hline $5 \mathrm{Fr}$ & 63 & 100.0 & - \\
\hline \multicolumn{4}{|l|}{ Catheter size (for PCI) (n=22) } \\
\hline $5 \mathrm{Fr}$ & 7 & 31.8 & - \\
\hline $6 \mathrm{Fr}$ & 15 & 68.2 & - \\
\hline \multicolumn{4}{|l|}{ No of catheter used ( $n=69)$} \\
\hline 1 & 46 & 66.7 & - \\
\hline 2 & 16 & 23.2 & - \\
\hline 3 & 7 & 10.1 & - \\
\hline \multicolumn{4}{|c|}{ Duration of sheath in situ in minutes (from insertion to removal) (n=69) } \\
\hline For CAG only & 18.3 & - & $<0.001$ \\
\hline For CAG \&/or PCI & 138.4 & - & \\
\hline
\end{tabular}

\section{Table-III}

Distribution of study population by their pre \& post-procedural test parameters

\begin{tabular}{|c|c|c|c|}
\hline \multirow[t]{2}{*}{ parameters } & \multicolumn{2}{|c|}{ Group } & \multirow[t]{2}{*}{ p-value } \\
\hline & $\begin{array}{c}\text { Pre-procedural } \\
\text { check up }(\mathrm{n}=69)\end{array}$ & $\begin{array}{l}\text { Post-procedural check up } \\
\text { (after } 3 \text { months) } \\
(\mathrm{n}=68) \\
\end{array}$ & \\
\hline Size of radial artery (mm) & $2.2 \pm 0.3$ & $2.1 \pm 0.3$ & 0.001 \\
\hline \multicolumn{4}{|l|}{ Reverse Barbeau test } \\
\hline Type A & $48(69.6 \%)$ & $34(50 \%)$ & - \\
\hline Type B & $21(30.4 \%)$ & $32(47.1 \%)$ & \\
\hline Type C & - & $2(2.9 \%)$ & \\
\hline $\mathrm{PSV}(\mathrm{cm} / \mathrm{s})$ & $67.0 \pm 34.7$ & $63.7 \pm 28.7$ & 0.488 \\
\hline $\mathrm{EDV}(\mathrm{cm} / \mathrm{s})$ & $5.2 \pm 0.7$ & $5.7 \pm 0.9$ & 0.633 \\
\hline $\mathrm{RI} \quad 0.9 \pm 0.1$ & $0.9 \pm 0.1$ & 0.419 & \\
\hline
\end{tabular}


Table-IV

Distribution of study population by their factors responsible for alteration of $R A D(n=68)$

\begin{tabular}{|c|c|c|c|}
\hline \multirow[t]{2}{*}{ Variable } & \multicolumn{2}{|c|}{ Size of radial artery } & \multirow[t]{2}{*}{ p-value } \\
\hline & $\begin{array}{c}\text { Reduced (n=22) } \\
\text { (Group-I) }\end{array}$ & $\begin{array}{c}\text { Normal }(\mathrm{n}=46) \\
(\text { Group-II) }\end{array}$ & \\
\hline \multicolumn{4}{|l|}{ Sex } \\
\hline Male & $11(50.0 \%)$ & $35(76.1 \%)$ & 0.032 \\
\hline Female & $11(50.0 \%)$ & $11(23.9 \%)$ & \\
\hline DM 16(72.7\%) & 28(60.9\%) & 0.338 & \\
\hline Duration of DM(Yrs) & $6.6 \pm 4.7$ & $8.1 \pm 7.2$ & 0.450 \\
\hline HTN $19(86.4 \%)$ & $36(78.3 \%)$ & 0.427 & \\
\hline DL $\quad 13(59.1 \%)$ & $26(56.5 \%)$ & 0.841 & \\
\hline Smoker & $6(27.3 \%)$ & $20(43.5 \%)$ & 0.198 \\
\hline PVD 1(4.5\%) & $2(4.3 \%)$ & 0.697 & \\
\hline \multicolumn{4}{|l|}{ Catheters Size (for PCI) } \\
\hline $5 \mathrm{Fr}$ & $18(81.8 \%)$ & $36(78.3 \%)$ & 0.734 \\
\hline $6 \mathrm{Fr}$ & $4(18.2 \%)$ & $10(21.7 \%)$ & \\
\hline \multicolumn{4}{|l|}{ No of catheters used } \\
\hline 1 & $15(68.2 \%)$ & $30(65.2 \%)$ & 0.115 \\
\hline 2 & $7(31.8 \%)$ & $9(19.6 \%)$ & \\
\hline 3 & $0(0.0 \%)$ & $7(15.2 \%)$ & \\
\hline Duration of Sheath in situ (min) & $51.5 \pm 14.5$ & $59.5 \pm 9.0$ & 0.624 \\
\hline
\end{tabular}

\section{Discussion:}

The adoption of trans-radial angiogram/angioplasty is increasing globally because of emerging data on its potential advantages over the trans-femoral approach. In RIVAL (Radial versus femoral access for coronary angiography and intervention in patients with acute coronary syndromes) and RIFLE-STEACS (Radial versus femoral randomized investigation in ST-Elevation acute coronary syndrome studies) trails there was significant clinical benefits in terms of both lower morbidity and cardiac mortality in patients with ST-segment elevation acute coronary syndrome. ${ }^{18-20}$ Other than the procedural failure in TCC due to radial artery spasm/ anatomical abnormality or failure of coronary artery cannulation, radial artery injury \& RAO are the concerning factors of TCC. In a study catheterized radial arteries on histopathological examination showed significantly more intimal hyperplasia, periarterial tissues or fat necrosis and adventitial inflammation. ${ }^{21}$ In another study using optical coherence tomography repeatedly accessed radial arteries showed more intimal tear \& thickening, medial dissection, and thrombi. ${ }^{22}$ These pathological and physiological changes may ultimately lead to RAO. In our study among 69 patients only one (1.45\%) elderly lady had RAO at third month follow-up which is pretty infrequent than in some studies (up to $18 \%$ ). ${ }^{1-7}$ This lady had no symptom or sign of ischemic hand but had undetectable radial flow by Doppler study. This may be explained by good collaterals and that's why Kiemeneij's recommendation was that the trans-radial procedure should be performed only in patients with a documented patent ulnar and palmar arch. ${ }^{23}$ This evaluation can be done by using the Allen's test, but Doppler ultrasound and plethysmography before the procedure are more accurate methods. ${ }^{24}$ Unfortunately in an international trans-radial practice survey in 2009-2010 by Bertrand et al. found that $23.4 \%$ of the respondents do not perform any pre-test. ${ }^{25}$ The mean diameter of radial artery was significant reduced $(\mathrm{p}=0.001)$ at third month follow-up in our study without any alteration of flow velocities. This findings matches with Wakeyama et al. from Japan who in their study by using IVUS found that the lumen diameter were smaller in repeat trans-radial intervention than in first time and this is due to intimamedia thickening. ${ }^{26}$ In another study radial artery diameter and vasodilatory properties were assessed by high resolution ultrasound at 10 to 14 months after TCC and found that radial artery diameter was reduced while vasodilatory properties were preserved. ${ }^{27}$ The only case of RAO in our study was a female and the reduction of mean radial artery diameter after TCC was significantly more in female $(\mathrm{p}=0.032)$. Several other studies have reported that female gender is a risk factor for RAO. ${ }^{28-30}$ 
The difference between genders in our study may be attributed to smaller diameter of radial artery in female found in our population in a study. ${ }^{17}$ Other than the gender discrepancy there were no relationship between reduction of RAD and diabetes (or with its duration), hypertension, dyslipidaemia, smoking or peripheral vascular disease. Size and number of catheter used and duration of vascular access sheath kept in the artery did not affect the reduction of diameter significantly.

The limitation of the study is that the study population is too small to strengthen the results. Although the experience of the operator has a significant impact on the work, this study was conducted in a centre where 95\% coronary angiogram and $70 \%$ of interventions were done through trans-radial approach.

Conclusion: Though the mean RAD of the study was smaller than other study population, but incidence of RAO is very low. RAD was significantly reduced after procedure without any clinical evidence of ischemia or alteration of flow velocity. Reduction of vessel caliber is more in female but no other factor was found to be affecting the diameter reduction.

\section{References:}

1. Zhou YJ, Zhao YX, Cao Z, et al. Incidence and risk factors of acute radial artery occlusion following transradial percutaneous coronary intervention. Zhonghua Yi Xue Za Zhi. 2007;87:1531-34.

2. Stella PR, Kiemeneij F, Laarman GJ, et al. Incidence and outcome of radial artery occlusion following transradial artery coronary angioplasty. Cathet Cardiovasc Diagn. 1997;40: 156-58.

3. Sanmartin M, Gomez M, Rumoroso JR, et al. Interruption of blood flow during compression and radial artery occlusion after transradial catheterization. Catheter Cardiovasc Interv. 2007;70:185-89.

4. Nagai S, Abe S, Sato T, Hozawa K, et al. Ultrasonic assessment of vascular complications in coronary angiography and angioplasty after transradial approach. Am J Cardiol. 1999;83:180-86.

5. Zankl AR, Andrassy M, Volz C, et al. Radial artery thrombosis following transradial coronary angiography: incidence and rationale for treatment of symptomatic patients with lowmolecular-weight heparins. Clin Res Cardiol. 2010;99:84147.

6. Kiemeneij F, Laarman GJ, Odekerken D, et al. A Randomized Comparison of Percutaneous Transluminal Coronary Angioplasty by the Radial, Brachial and Femoral Approaches: the ACCESS study. J Am Coll Cardiol. 1997;29:1269-75.

7. Pancholy SB. Transradial access in an occluded radial artery: New technique. J Invasive Cardiol. 2007;19:541-44
8. Kotowyez MA, Dzavik V. Radial Atrtry Patency After Transradial Catheterization, Circ Cardiovascular Interv 2012;5:127-33.

9. Jolly SS, Yusuf S, Cairns J, Niemela K, et al. Radial Versus Femoral Access for Coronary Angiography and Intervention in Patients With Acute Coronary Syndromes (RIVAL): a randomised, parallel group, multicentre trial. Lancet. 2011; $377: 1409-20$.

10. Yoo BS, Yoon J, Ko JY, Kim JY, et al. Anatomical consideration of the radial artery for transradial coronary procedures: arterial diameter, branching anomaly and vessel tortuosity. Int J Cardiol. 2005;101:421- 27.

11. Spaulding C, Lefevre T, Funck F, et al. Left radial approach for coronary angiography: results of a prospective study. Cathet Cardiovasc Diagn. 1996;39:365-70

12. Davis FM, Stewart JM. Radial artery cannulation: a prospective study in patients undergoing cardiothoracic surgery. Br J Anaesth. 1980;52:41-47.

13. Bedford RF, Wollman H. Complications of percutaneous radialartery cannulation: an objective prospective study in man. Anesthesiology. 1973;38:228-36.

14. Slogoff S, Keats AS, Arlund C. On the safety of radial artery cannulation. Anesthesiology. 1983;59:42-47.

15. Cubero JM, Lombardo J, Pedrosa C, et al. Radial Compression Guided by Mean Artery Pressure Versus Standard Compression With a Pneumatic Device (RACOMAP). Catheter Cardiovasc Interv.2009;73:467-72.

16. Pancholy SB, Patel TM. Effect of duration of hemostatic compression on radial artery occlusion after transradial access.Catheter Cardiovasc Interv. 2012;79:78-81.

17. Chowdhury MZ, Gomes HI, Kabir CMS, et al. Radial \& ulnar artery size in Bangladeshi population coming for catheterization. Ibrahim Cardiac Medical Journal 2013; 3 (1 \& 2): 21-26.

18. Jolly SS, Yusuf S, Cairns et al. Radial versus femoral access for coronary angiography and intervention in patients with acute coronary syndromes (RIVAL): A randomised, parallel group, multicentre trial. Lancet.2011;377:1409-20

19. Mehta Sr, Jolly SS, Cairns. et al. Effects of radial versus femoral artery access in patients with acute coronary syndromes with or without ST-segment elevation. J Am Coll Cardiol. 2012;60:2490-9

20. Romagnoli E, Biondi-Zoccai G, Sciahbasi A. et al. Radial versus femoral randomized investigation in ST-segment elevation acute coronary syndrome: The RIFLE-STEACS (Radial Versus Femoral Randomized Investigation in ST-Elevation Acute Coronary Syndrome) study. J Am Coll Cardiol. 2012;60:248

21. The Global Use of Strategies to Open Occluded Coronary Arteries in Acute Coronary Syndromes (Gusto IIB) Angioplasty Substudy Investigators. N Engl J Med 1997;336:1621-28.

22. Caputo RP, Kalon KL, Stoler RC, et.al. Effect of continuous quality improvement analysis on the delivery of primary percutaneous transluminal coronary angioplasty for acute myocardial infarction. Am J Cardiol 1997;79:1159-64. 
23. Bertrand OF, Rao SV, Pancholy S, Jolly SS, et al. Transradial approach for coronary angiography and interventions: results of the first international transradial practice survey. JACC Cardiovasc Interv 2010;3:1022-31.

24. Wakeyama T, Ogawa H, Iida H, et al. Intima-Media Thickening of the Radial Artery After Transradial Intervention. An Intravascular Ultrasound Study. JACC 2003; 41(7):1109-14.

25. Madssen E, Haere P, Wiseth R. Radial Artery Diameter and Vasodilatory Properties After Transradial Coronary Angiography. The Annals of Thoracic Surgery. 2006;82(5): 1698-1702.

26. Tuncez A, Kaya Z, Aras D, et al. Incidence and Predictors of Radial Artery Occlusion Associated Transradial Catheterization. .Int J Med Sci 2013; 10(12):1715-19.
27. Stella PR, Kiemeneij F, Laarman GJ, et al. Incidence and outcome of radial artery occlusion following transradial artery coronary angioplasty. Cathet Cardiovasc Diagn. 1997;40: 156-8

28. Nagai S, Abe S, Sato T, et al. Ultrasonic assessment of vascular complications in coronary angiography and angioplasty after transradial approach. AmJ Cardiol. 1999;83:180-86

29. Yoo BS, Lee SH, Ko JY. et al. Procedural outcomes of repeated transradial coronary procedure. Catheter Cardiovasc Interv. 2003;58:301-4

30. Sanmartin M, Gomez M, Rumoroso JR. et al. Interruption of blood flow during compression and radial artery occlusion after transradial catheterization. Catheter Cardiovasc Interv. 2007;70:185-9. 